\title{
RENAL LESIONS- AN EXPERIENCE IN RURAL AREA OF ANDHRA PRADESH
}

\author{
Dukkipati Kalyani1 ${ }^{1}$ R. Vijayabhaskar ${ }^{2}$
}

${ }_{1}^{1}$ Assistant Professor, Department of Pathology, Rangaraya Medical College, Kakinada, Andhra Pradesh.

2Professor and HOD, Department of Pathology, Rangaraya Medical College, Kakinada, Andhra Pradesh.

\section{ABSTRACT}

\section{BACKGROUND}

Renal cancers include a spectrum of pathologies that may challenge the clinician in choosing the optimal treatment. Correct identification of the lesion may be difficult and the appropriate surgical procedure is paramount for lesions suspected to be malignant. The purpose of this article is to provide a comprehensive overview regarding the spectrum of rare renal tumours especially malignant tumours.

Aim- To study the various types of renal lesions with special emphasis on renal tumours with unusual presentation.

\section{MATERIALS AND METHODS}

31 cases of renal lesions were studied at Department of Pathology, Rangaraya Medical College, Kakinada during three year period (November 2013 to October 2016) after correlating the histopathological findings with clinical, preoperative imaging and intraoperative findings. The lesions identified were both neoplastic and nonneoplastic conditions. Three out of ten cases of renal tumours were presented with unusual presentation.

\section{RESULTS}

Out of total 31 cases 15 cases were neoplastic and 16 cases were nonneoplastic. Out of neoplastic conditions, 12 cases were malignant and 3 case was benign. The various lesions identified were Conventional Renal cell carcinoma (Clear cell type), Papillary type of renal cell carcinoma, Adult Nephroblastoma (cystic partially differentiated nephroblastoma), Nephroblastoma with biphasic pattern, inflammatory leiomyosarcoma, Angiomyolipoma, Hydronephrosis and Hypoplastic dysplasia with chronic pyelonephritis, xanthogranulomatous pyelonephritis, tuberculous pyelonephritis, and chronic interstitial nephritis. Two cases of Wilms tumours (Nephroblastoma) with unusual presentation and one case of Papillary renal cell carcinoma were diagnosed. 3 out of 31 cases were presented with unusual presentation.

\section{CONCLUSION}

Renal masses that are seen within the paediatric and adult population remain a delicate and sensitive issue. A combination of pathologic rarity, complexity, and uncertain malignant potential may lead to aggressive treatment. Advancements in diagnostic modalities are required for better diagnosis and treatment strategies for these challenging masses.

\section{KEYWORDS}

Nephroblastoma, Renal Cell carcinoma, Biphasic Pattern, Papillary.

HOW TO CITE THIS ARTICLE: Kalyani D, Vijayabhaskar R. Renal lesions- an experience in rural area of Andhra Pradesh. J. Evolution Med. Dent. Sci. 2017;6(2):79-83, DOI: 10.14260/Jemds/2017/20

\begin{tabular}{|c|c|}
\hline BACKGROUND & This article reviews solid and cystic renal masses \\
\hline $\begin{array}{l}\text { Many renal tumours were previously lump } \\
\text { categorized as Renal cell carcinomas. Hon } \\
\text { vears several specific tumours have been }\end{array}$ & $\begin{array}{l}\text { including the rare presentations in children and adults, with } \\
\text { an emphasis on clinical information, imaging and }\end{array}$ \\
\hline
\end{tabular}
distinct pathologic entities. The diagnosis of these lesions can be suggested by their unique clinical history, such as age at presentation, distinctive imaging features and intraoperative findings. Knowledge of these lesions can help to suggest a specific diagnosis and management. However, even when the most sophisticated imaging techniques are used, renal neoplasms cannot always be diagnosed with preoperative imaging.

Financial or Other, Competing Interest: None.

Submission 23-10-2016, Peer Review 24-12-2016,

Acceptance 30-12-2016, Published 05-01-2017.

Corresponding Author:

Dr. Dukkipati Kalyani,

Assistant Professor,

Department of Pathology,

Rangaraya Medical College,

Kakinada-533001, Andhra Pradesh.

E-mail:dukkipati29@gmail.com

DOI: $10.14260 /$ jemds $/ 2017 / 20$

\section{MATERIALS AND METHODS}

This study has been conducted in the department of Pathology, Rangaraya Medical College, Kakinada during one year period from November 2013 to October 2016. The data including age, sex, tumour site, intraoperative findings and radiological findings were collected. This study comprises of 31 consecutive cases of renal masses in all age groups admitted in the departments of Urology and Paediatric surgery, Rangaraya Medical College, Kakinada during the period from November 2013 to October 2016. Patients who died before any therapeutic measure, patients who left the hospital against medical advice were excluded from our study.

Radical/partial nephrectomy were done in all cases. Following surgery, specimens were sent for histopathological evaluation. The specimens were examined grossly and bits were taken from representative areas (Including the ureter, renal vessels, renal sinus, perinephric fat with lymph nodes). 
In all these cases, the slides were stained with Haematoxylin and Eosin. The histopathological findings were correlated with clinical, preoperative imaging and intraoperative findings. The results were reviewed after histological typing. Grading and staging were also done for all malignancies.

\section{RESULTS}

Total number of cases studied were 31 . Out of these 15 cases were neoplastic and 16 cases were nonneoplastic lesions [Figure 1]. Various histological types were described in Table $1 \&$ Figure 2]. The most common tumour was Renal cell carcinoma (clear cell type) with 9 cases (29.05\%), 3 cases of Papillary renal cell carcinoma (9.67 \%) followed by 2 cases of Wilms tumour (6.48 \%) and 1 case of inflammatory leiomyosarcoma (3.22\%) and 3 cases of Angiomyolipoma $(9.67 \%)$ cases. Among the non-neoplastic lesions 4 cases of chronic pyelonephritis (12.90\%), 2 cases (6.48\%) of Hydronephrosis, 2 cases of Hypoplastic dysplasia with pyelonephritis $(6.48 \%), 1$ case $(3.22 \%)$ of xanthomatous pyelonephritis, tuberculous pyelonephritis, cystic renal dysplasia with chronic pyelonephritis, chronic interstitial nephritis, and hydronephrosis with chronic pyelonephritis each were diagnosed.
In three cases, there was no clinical suspicion. The clinical, preoperative imaging and intraoperative findings for these cases were described in Table 2 whereas the gross and histopathological findings were shown in Table 3 [Figures 3 13]. These cases were presented with rare clinical presentation and histological type.

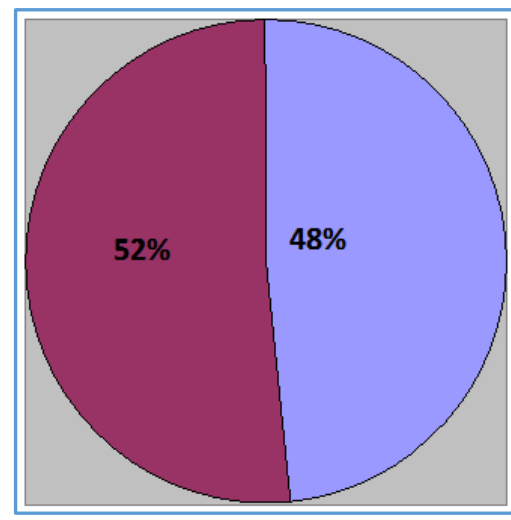

Figure 1. Distribution of malignancy nature of renal tumours

\begin{tabular}{|c|c|c|}
\hline \multirow{2}{*}{ Histological type } & \multicolumn{2}{|c|}{ Number of Cases } \\
\hline & Number & Percentage \\
\hline \multicolumn{3}{|l|}{ Malignant Lesions } \\
\hline Conventional renal cell carcinomas (Clear cell type) & 9 & $29.05 \%$ \\
\hline Papillary renal cell carcinoma & 3 & $9.67 \%$ \\
\hline Adult Nephroblastoma (cystic partially differentiated nephroblastoma) & 1 & $3.22 \%$ \\
\hline Nephroblastoma (biphasic pattern) & 1 & $3.22 \%$ \\
\hline inflammatory leiomyosarcoma & 1 & $3.22 \%$ \\
\hline \multicolumn{3}{|l|}{ Benign Lesions } \\
\hline Angiomyolipoma & 3 & $9.67 \%$ \\
\hline \multicolumn{3}{|l|}{ Nonneoplastic Conditions } \\
\hline Hydronephrosis & 2 & $6.48 \%$ \\
\hline Hypoplastic dysplasia with pyelonephritis & 2 & $6.48 \%$ \\
\hline xanthomatous pyelonephritis & $\mathbf{1}$ & $3.22 \%$ \\
\hline tuberculous pyelonephritis & 1 & $3.22 \%$ \\
\hline chronic interstitial nephritis cystic renal dysplasia with chronic pyelonephritis & 1 & $3.22 \%$ \\
\hline hydronephrosis with chronic pyelonephritis & $\mathbf{1}$ & $3.2 \mathrm{~s} 2 \%$ \\
\hline Total & 10 & $100 \%$ \\
\hline
\end{tabular}

\begin{tabular}{|c|c|c|c|}
\hline Category & Case 1 & Case 2 & Case 3 \\
\hline Age/Sex & $25 / \mathrm{M}$ & 7 months/M & $45 / \mathrm{M}$ \\
\hline Clinical & Left renal abscess & Left Renal tumour & Right renal tumour \\
\hline Radiology findings & $\begin{array}{c}\text { Left renal abscess/ } \\
\text { pyonephrosis on ultrasound }\end{array}$ & \begin{tabular}{|c|} 
Heterogenous mass in the left \\
kidney measuring $12 \times 10 \mathrm{~cm}$. No \\
calcified areas were noted. Renal \\
pelvis and renal vein were not \\
involved. The other abdominal \\
viscera were normal. There was \\
no lymph node enlargement.
\end{tabular} & $\begin{array}{l}\text { An echogenic mass in the upper } \\
\text { part of the right kidney } \\
\text { measuring } 4 \mathrm{X} 3 \mathrm{~cm} \text { with focal } \\
\text { calcified areas. The renal sinus is } \\
\text { involved. The other abdominal } \\
\text { viscera were normal. There was } \\
\text { no lymph node enlargement. }\end{array}$ \\
\hline Intra operative & $\begin{array}{l}2 \times 20 \mathrm{~cm} \text { renal abscess along } \\
\text { superior pole of left kidney. } \\
\text { Inferior part of left kidney is } \\
\text { viable. About } 2 \text { litres of pus } \\
\text { was aspirated }\end{array}$ & $\begin{array}{l}\text { Grossly enlarged Left Kidney with } \\
12 \times 10 \mathrm{~cm} \text { grey white solid tumour }\end{array}$ & $\begin{array}{l}\text { Right kidney with solid tumour } \\
\text { measuring } 5 \times 4 \mathrm{~cm} \text { in the lower } \\
\text { pole that extends into the renal } \\
\text { sinus. }\end{array}$ \\
\hline Clinical diagnosis & Renal abscess & Nephroblastoma & Renal cell Carcinoma \\
\hline \multicolumn{4}{|c|}{ Table 2. Clinical summary of rare presentations } \\
\hline
\end{tabular}




\begin{tabular}{|c|c|c|c|}
\hline Sl. No. & Gross Pathology & Histopathology & Final Diagnosis \\
\hline Case 1 & $\begin{array}{c}\text { 14x11x8 cm partial nephrectomy } \\
\text { specimen with cystic cut surface filled } \\
\text { with haemorrhage and necrosis. } \\
\text { Capsule is adherent. }\end{array}$ & $\begin{array}{c}\text { Wilms Tumour with epithelial, mesenchymal } \\
\text { and blastemal cells. There is associated abscess } \\
\text { with inflammation and eosinophilic bodies. }\end{array}$ & $\begin{array}{c}\text { Adult Wilms Tumour } \\
\text { (cystic partially } \\
\text { differentiated } \\
\text { nephroblastoma) }\end{array}$ \\
\hline Case 2 & $\begin{array}{c}12 \times 9 \times 6 \text { cm radical nephrectomy } \\
\text { specimen with grey white solid tumour } \\
\text { occupying entire cut surface with rim of } \\
\text { compressed normal renal parenchyma at } \\
\text { one pole and adherent capsule. }\end{array}$ & $\begin{array}{c}\text { Wilms Tumour with predominant } \\
\text { mesenchymal elements with intervening } \\
\text { epithelial component. }\end{array}$ & $\begin{array}{c}\text { Biphasic Nephroblastoma } \\
\text { with predominantly } \\
\text { mesenchymal component }\end{array}$ \\
Case 3 & $\begin{array}{c}\text { 4x3.5x3 cm well defined grey white mass } \\
\text { at lower pole of right kidney with } \\
\text { adherent capsule at tumour site. Renal } \\
\text { sinus is grossly involved by the tumour. }\end{array}$ & $\begin{array}{c}\text { Renal cell carcinoma papillary type with } \\
\text { psammoma bodies. Renal sinus is infiltrated by } \\
\text { the tumour. }\end{array}$ & $\begin{array}{c}\text { TypeI Papillary renal cell } \\
\text { carcinoma (Histological } \\
\text { grade 1) with infiltration of } \\
\text { renal sinus. }\end{array}$ \\
\hline
\end{tabular}

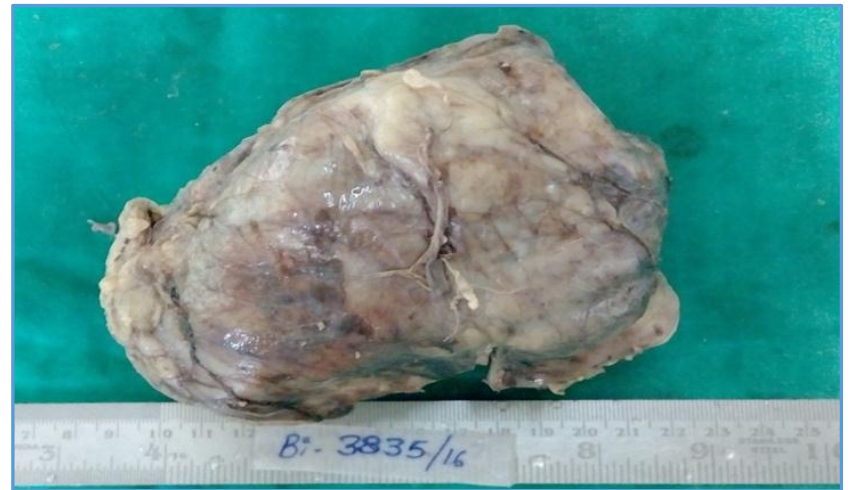

Figure 2. Gross photograph of Partial nephrectomy with cystic renal tumour

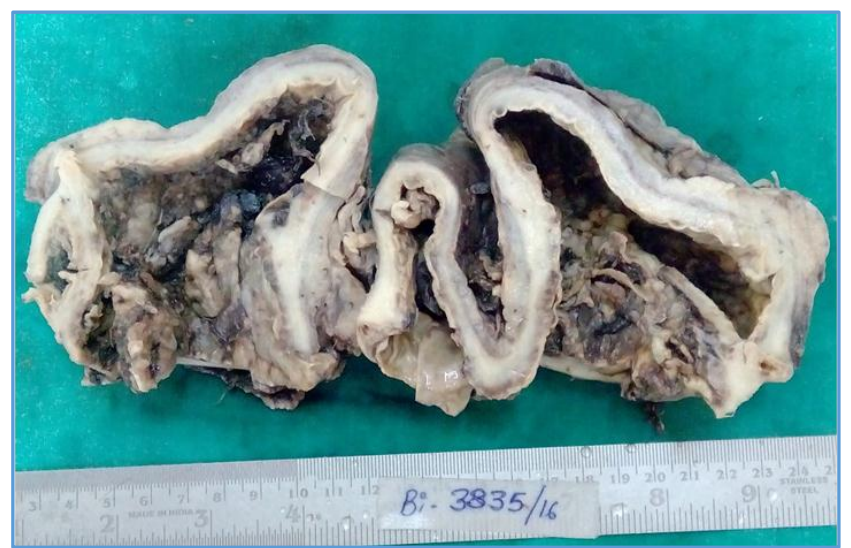

Figure 3. Gross photograph of cut section of partial nephrectomy specimen with cystic renal tumour

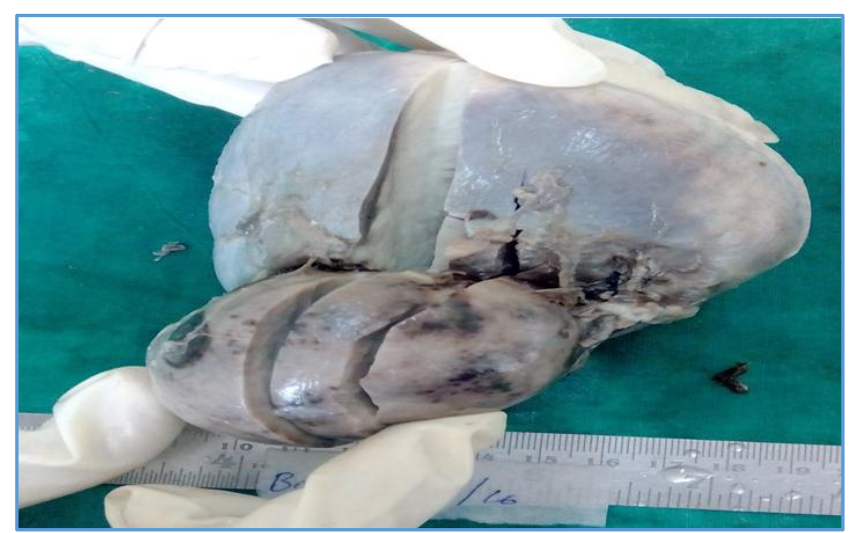

Figure 4. Gross photograph of Nephrectomy specimen with Wilms' Tumour

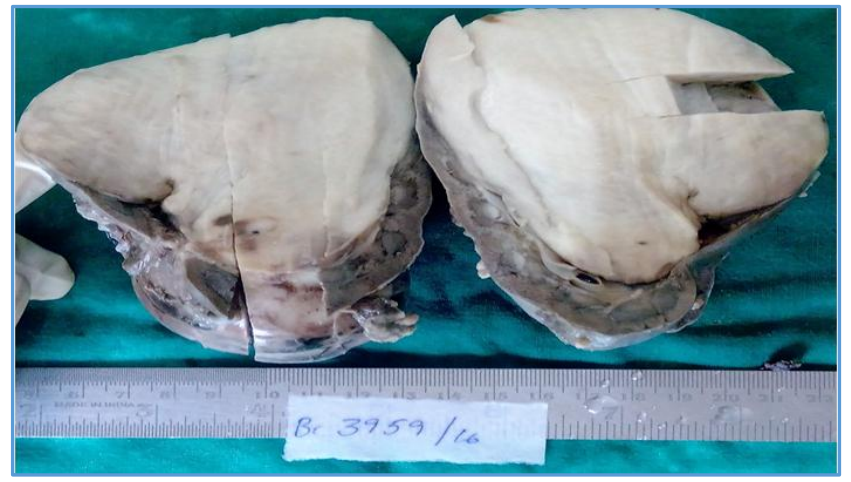

Figure 5. Gross photograph of Wilms' tumour with grey white solid cut surface with adjacent rim of renal parenchyma

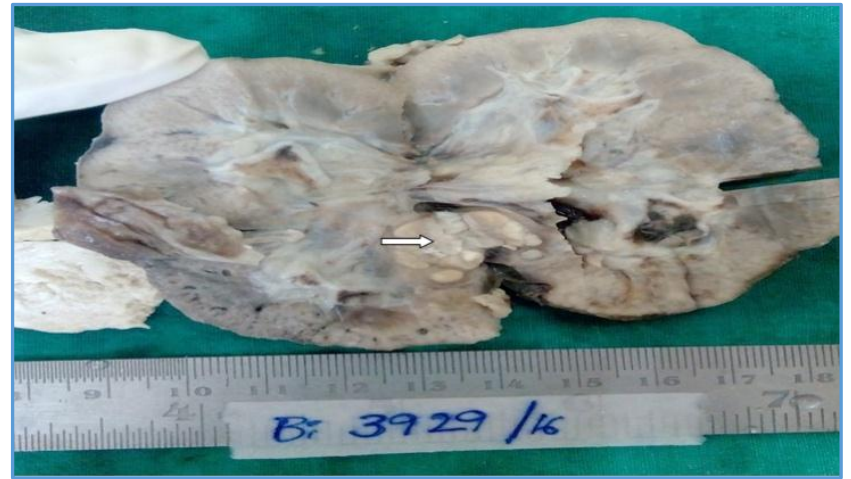

Figure 6. Gross photograph of papillary renal carcinoma

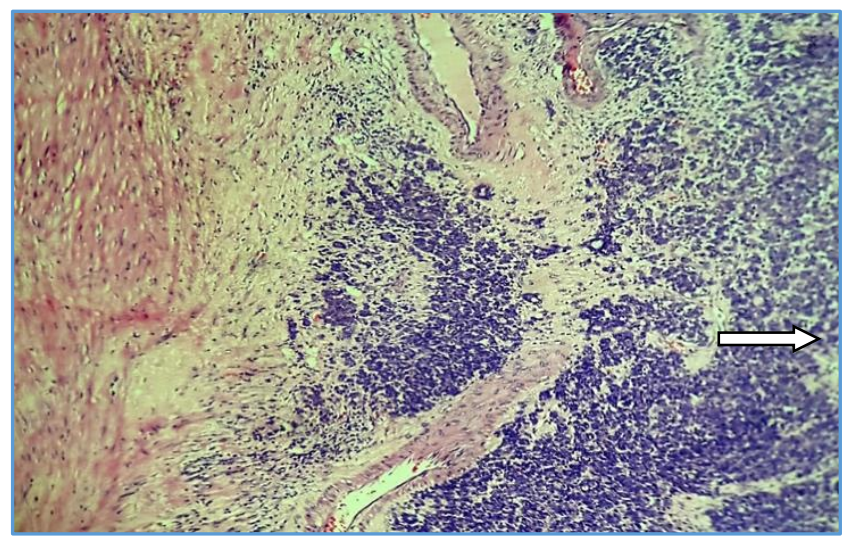

Figure 7. Adult Wilms' Tumour with blastemal, stromal and epithelial components, H\&E 10X 


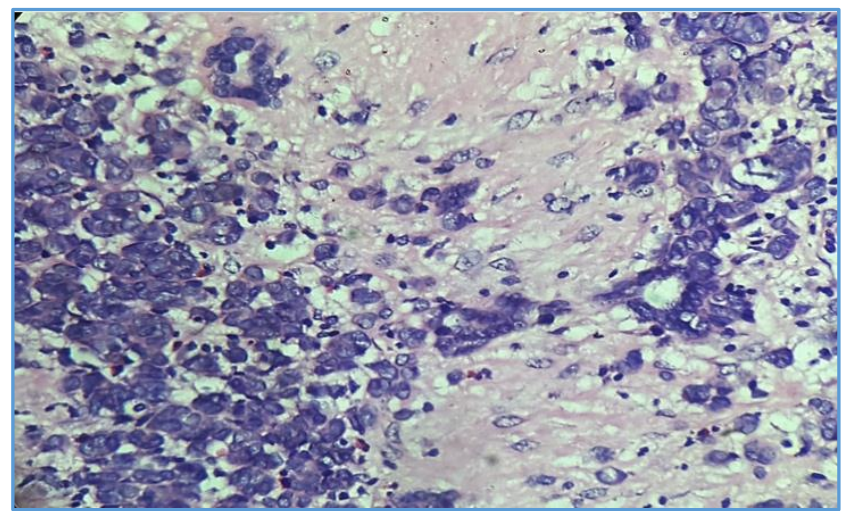

Figure 8. Adult Wilms' tumour, H \& E 40x

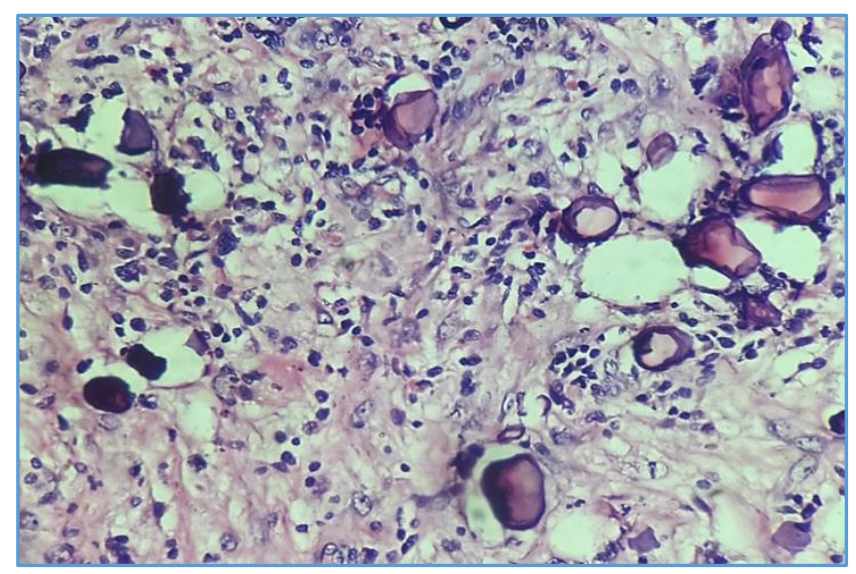

Figure 9. Renal Abscess in Adult Wilms' Tumour with eosinophilic bodies $\mathrm{H} \& \mathrm{E} 40 \mathrm{X}$

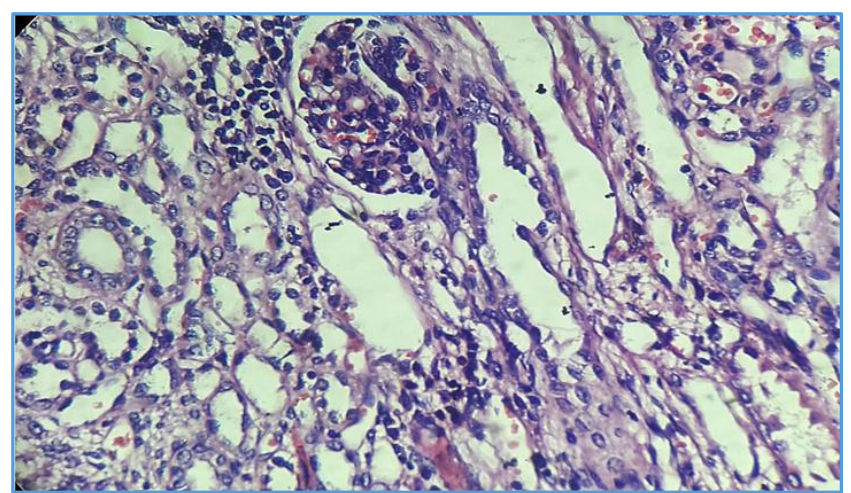

Figure 10. Adult Wilms' tumour with epithelial elemts with adjacent renal parenchyma, H\&E 40X

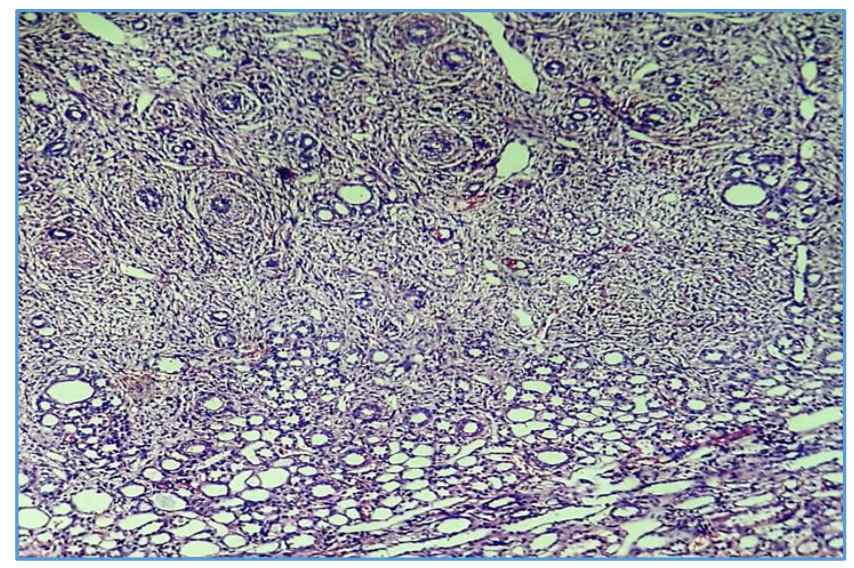

Figure 11. Biphasic Wilms' tumour with predominantly mesenchymal component $\mathrm{H} \& \mathrm{E}, 10 \mathrm{X}$

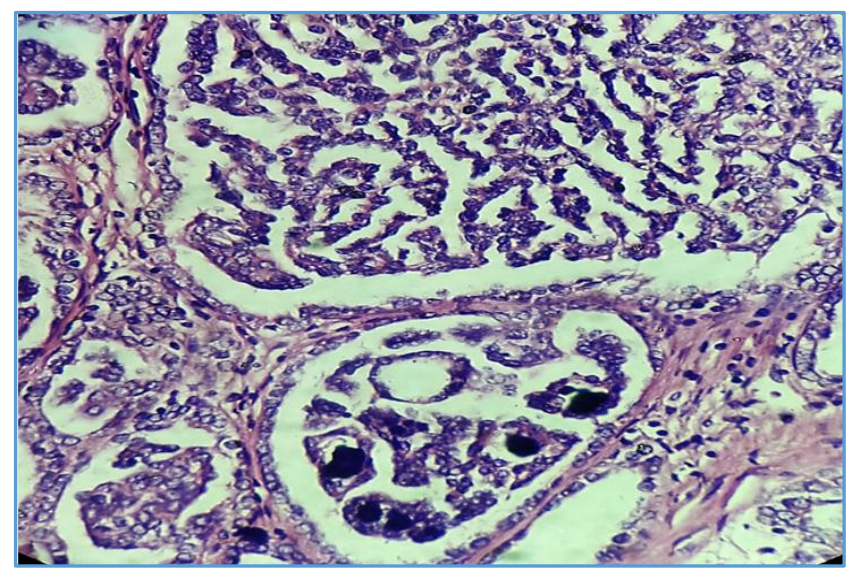

Figure 12. Type 1 Papillary renal cell carcinoma

(Grade 1) with psammoma bodies, H\&E 40X

\section{DISCUSSION}

Renal tumours may be discovered during routine clinical examination or incidentally during the course of diagnostic or therapeutic procedures for other causes. The key challenge is distinguishing malignant neoplasms from benign masses. Wilms' tumour (Nephroblastoma) is the most common renal neoplasm of childhood and it has the highest probability of long-term survival with an overall cure rate of approximately $90 \%$. Nephroblastoma usually occurs before 6 years and is rare in adults. In adults it has a worse prognosis than in the paediatric population.[1] Classic Wilms' tumour is composed of three types of cells - blastemal, stromal, and epithelial; although the occurrence of all three types in the same case is uncommon mainly in adult Nephroblastoma. ${ }^{2]}$

The diagnostic criteria defining adult Nephroblastoma described by Kilton et al[3] include the tumour under consideration should be a primary renal neoplasm; presence of primitive blastemic spindle or round cell component; formation of abortive or embryonal tubules or glomerular structures; no area of tumour diagnostic of renal cell carcinoma; confirmation of histology, an patient's age $>15$ years. This disease is difficult to differentiate from renal cell carcinoma based only on imaging techniques. Rapidly growing abdominal mass in a young patient, with heterogeneous contrast uptake on ultrasound, and surrounded by a pseudocapsule on CT is suggestive of Wilms' tumour. Preoperative diagnosis may be suggestive in about $75-80 \%$ of cases. The histopathological study confirms the diagnosis. Aggressive treatment, including radical surgery, chemotherapy, and irradiation of the tumour bed, is considered necessary. The differential diagnosis of an adult Wilms' tumour with mainly epithelial differentiation includes metanephric adenoma. A predominant blastemic Wilms' tumour has a strong resemblance to small, blue round cell tumours.

Most adults present with local pain and haematuria, in contrast to the palpable boggy mass which is more common in children. In adults, Wilms' tumour is larger and ill-defined mass with areas of necrosis and haemorrhage. About half of the patients have stage 3 or 4 disease. ${ }^{[4]}$ But in our case the patient presented with an unusual presentation. Ultrasound revealed a renal abscess in left kidney which was a cystic mass filled with haemorrhage and pus. Partial nephrectomy was done for the patient. Intraoperative findings were correlated with imaging findings. 
But on histological examination the case was diagnosed as Adult Nephroblastoma (Cystic partially differentiated Nephroblastoma) as there were epithelial, mesenchymal and blastemal components. This presentation of Nephroblastoma as cystic renal tumour is very rare. Blastemal component was predominant in the histology in 6 out of the 8 adult Wilms' Tumour reported in Indian literature.[5,6] Although the prognosis is poorer than that of children when the disease is compared stage for stage, the outcome for adult patients diagnosed with Wilms' tumour is steadily improving.

Wilms' tumour consist of blastemal, stromal and epithelial elements, any one of which may be predominant. When one component occupies more than $65 \%$ of the crosssectional area of tumour, the pattern is subtyped as predominant (Blastemal/epithelial/stromal/predominant). When no single component predominates the tumour is referred to as one of mixed pattern. The basic microscopic pattern of Wilms' tumour is a biphasic growth composed of islands of metanephric blastema (compact arrangement of small oval/polygonal cells with hyperchromatic nuclei and scant cytoplasm) separated by mesenchyme. Variable epithelial differentiation usually in the form of tubules showing degrees of lumen-formation may be present with infrequent Glomeruloid structures. There are few studies reported where Wilms' tumour of biphasic pattern (predominantly mesenchymal component.

In the context of modern chemotherapy the predominant element is not of prognostic significance, although blastemal tumours as a group have a poor outcome because they tend to present a more advanced stage. In our study one case has predominantly mesenchymal component with intervening tubular elements were seen. The diagnosis of Wilms' tumour is usually not problematic in untreated nephrectomy specimens if the differential diagnosis are kept in mind.

Papillary renal cell carcinoma was individualized from other renal cell carcinomas by its predominantly papillary or tubulo-papillary architecture ( $>75 \%$ of the tumour; 1$)$. The prognosis of papillary renal cell carcinoma remains debatable in the literature. Previous studies reported a better prognosis than conventional clear renal cell carcinoma.[7,8,9] Recently, two morphologic types of papillary renal cell carcinoma were described based on microscopic criteria. Several other studies confirmed that papillary renal cell carcinomas composed of Type 1 have a lower Furhman grade and a lower-stage when compared to Type 2 and with good prognosis. ${ }^{[8,10]}$ Onishi et al confirmed also that the prognosis is better in basophilic tumours (Type 1) than in eosinophilic tumours (Type 2).[9] In contrast, the stage TNM and the tumour size were not significantly different between Type 1 and 2. In a more recent publication, Delahunt et al[10] concluded that morphologic typing of papillary renal cell carcinoma is an independent predictive factor of outcome on multivariate analysis. According to many studies, the Fuhrman grade remains a valuable prognostic factor of papillary renal cell carcinomas.[10,11] In conclusion, our findings confirmed that the morphologic subtyping is an important prognostic factor of papillary renal cell carcinoma.

\section{CONCLUSION}

A thorough understanding of the profile of common renal masses, as well as their associated clinical and imaging features, can facilitate accurate preoperative diagnosis and optimize patient care. This article comprehensively summarizes the history, imaging, histopathology and provides the rationale for choice of the correct surgical procedure of rare renal tumours. We report these renal tumours because of their rarity in clinical presentation and histological type.

\section{REFERENCES}

[1] Hentrich MU, Meister P, Brack NG, et al. Adult Wilms tumour. Report of two cases and review of the literature. Cancer 1995;75(2):545-51.

[2] Sparano JA, Beckwith JB, Mitsudo S, et al. Complete remission in refractory anaplastic adult Wilms tumour treated with cisplatin and etoposide. Cancer 1991;67(4):956-9.

[3] Kilton L, Matthews MJ, Cohen MH. Adult Wilms tumour: report of prolonged survival and review of literature. J Urol 1980;124(1):1-5.

[4] Roth DR, Wright J, Cawood CD, et al. Nephroblastoma in adults. J Urol 1984;132(1):108-10.

[5] Biswal BM, Lal P, Deo SV, et al. Multidisciplininary management of adult Wilms tumour. JIMA 1995;93(11):433-4.

[6] Wadhwa N, Mishra K, Agarwal S. Wilms tumour in adults: a report of three cases. Indian J Pathol Microbiol 2005;48(2):235-8.

[7] Onishi T, Ohishi $\mathrm{Y}$, Goto $\mathrm{H}$, et al. Papillary renal cell carcinoma: clinicopathological characteristics and evaluation of prognosis in 42 patients. Br J Urol 1999;83(9):937-43.

[8] Fuhrman SA, Lasky LC, Limas C. Prognostic significance of morphologic parameters in renal cell carcinoma. Am J Surg Pathol 1982;6(7):655-63.

[9] Kovacs G, Fuzesi L, Emanuel A, et al. Cytogenetics of papillary renal cell tumours. Genes Chromosomes Cancer 1991;3(4):249-55.

[10] Amin MB, Corless CL, Renshaw AA, et al. Papillary (chromophil) renal cell carcinoma: histomorphologic characteristics and evaluation of conventional pathologic prognostic parameters in 62 cases. Am J Surg Pathol 1997;21(6):621-35.

[11] Delahunt B, Eble JN, McCredie MR, et al. Morphologic typing of papillary renal cell carcinoma: comparison of growth kinetics and patients survival in 66 cases. Hum Pathol 2001;32(6):590-5. 